\title{
A dual device scenario for informal language learning: interactive television meets the mobile phone
}

\author{
Sanaz Fallahkhair, Lyn Pemberton, Judith Masthoff, \\ School of Computing and Information Sciences, University of Brighton \\ \{S.Fallahkhair, Judith.Masthoff,Lyn.Pemberton\}@brighton.ac.uk
}

\begin{abstract}
Researchers have investigated the possibilities for supporting language learning through a range of technologies, most recently mobile phones and interactive television (iTV). Drawing on a focus group study, we present a scenario demonstrating an approach that blends the features of these two technologies. Three areas are identified for further exploration: pedagogy, technical feasibility and interaction design issues.
\end{abstract}

\section{Introduction}

Scenarios are a well-established representation in user-centred design for embodying user requirements and early design concepts [1]. Using scenarios can help achieve the goal of creating truly useful and usable products by encouraging designers "to explore the larger design space of many possible design challenges, to review the technical feasibility and likely payoffs of the different approaches and only then begin considering the normal design issues" [2]. This is particularly important in designing applications for relatively novel activities that need to be embedded in complex social contexts. Researchers designing for ubiquitous technologies such as mobile phones and interactive television have frequently taken a scenariobuilding approach. For instance, scenarios have been used for conceptualising learning applications in mobile devices $[3,5]$ and interactive television (iTV) $[4,6]$, including language learning $[7,8]$ To achieve realism, scenarios need to be grounded in the results of other forms of requirements work, such as observational studies or surveys. This allows the scenario builders to have confidence in their assumptions and provides access to real-life models allowing personas to be richly represented [9]. In this paper we use the results of a focus group study reported in [10] to generate a rich scenario for informal language learning via a combination of two technologies, mobile phone and iTV.

\section{Focus group}

\subsection{Methodology}

The context for the study reported here is a development programme for learning with interactive television. Twenty-one participants took part in the study, in three groups. Participants were a self-selecting group, recruited amongst the staff and student population of a UK university. The ten female and eleven male participants were of varied ages, nationalities and language backgrounds. They had reached different levels of foreign language competence, from a professed complete inability to learn any foreign language up to degree level and beyond. Each focus group explored participants' motivations for learning a language and their preferred approaches, including their use of and attitudes to information and communication technologies to support foreign language acquisition.

\subsection{Results}

A large number of desirable attributes for learning environments emerged, some of them contradictory. For instance, while participants appreciated the routine of the language classroom, having to attend classes imposed an inflexible schedule on busy people. It was clear that no single approach would be likely to satisfy all requirements, and participants recognised this, with the majority of those who attended a formal class also using complementary methods. A full account of the results is found in [10] but here we concentrate on the results most relevant to the development of dual device learning technologies.

\section{Authentic materials}

Participants were enthusiastic about authentic materials of all kinds. Reading novels, watching films and listening to the radio were mentioned as ways of getting the brain to "tune in". Some participants reported trying to recreate elements of immersion at home, for instance listening to a foreign language radio station or labelling 
domestic objects in the foreign language. Participants also recognised the importance of learning about the target culture as well as the language. One native Arabic speaker, for instance, mentioned that he had found it very useful to watch Coronation Street (a popular UK soap opera), saying "I could improve my English and understand English culture a bit more". Participants appreciated the fact that the authentic material delivered by television was itself engaging. Television in particular was perceived as more like entertainment than learning: "...you can actually sit back and relax".

\section{Learning in context}

The notion of learning in context was raised by several participants. A particular problem was the difficulty of applying a language item learned in one context to a different one. A solution used by some was the use of a combination of media, with one providing context for the other: for instance, watching the news on television and then reading the same news stories in a newspaper. Foreign language television was seen as a valuable medium here. Although speech might be perceived as fast, with background noise sometimes obscuring the speech soundtrack, participants liked the context provided by the visual information, which made it easier to determine what was being said: "I just watch TV in French, I don't understand everything, but especially with soap operas, there is so much gesture". This success in understanding also makes the experience rewarding even if the language is hard to unravel.

\section{Learning on the move}

Participants liked being able to fit learning into odd moments of their day, for instance when travelling. Several listened to language tapes or CD-ROMs when driving, or tuned the car radio to a foreign language station. The fact that the mobile phone could be used on the move, e.g. in a bus or train, was attractive to these participants, who particularly liked the potential of SMS for language learning. One participant had used a Chinese service that sent subscribers text messages with new English words or constructions to learn [11]. However, there was a distinct generation gap where mobiles were concerned. Younger participants were enthusiastic, but the over 50's were distinctly cool: "I don't use a mobile phone, and I wouldn't use it to learn about a language ... I think it is a terrible idea".

\section{Scaffolding}

Participants used current facilities such as subtitling and closed captions to scaffold their learning. One advantage of target language subtitling was the fact that it anchored speech in written form, making it possible for the learner to find unknown terms to be looked up in a dictionary. The non-UK participants made extensive use of English language closed captions (aimed at deaf viewers) to support their learning of English. However, speed was a problem: "subtitles ... I found that really difficult for me because I couldn't go that fast." The DVD, providing functionality similar to iTV, was familiar and was valued for its flexibility, its extra material, such as subtitles and extra audio channels, and the user control it affords.

\section{Usage patterns of (I)TV}

None of the participants had used interactive TV for language learning, nor were they particularly impressed with the current state of iTV technology and services. Usability was perceived as a problem: "the remote control is just not usable ... by the time you figure out what button to press you miss the content". This was a particular problem for the less motivated viewer: "if a semi-interested adult decides to use their spare time [to learn a language via TV] and they can't find out what they want to know about getting started, they might just get up and say 'Poof, forget about it"'. Participants were anxious about missing part of the TV programme, while looking up additional information: "if information is available during a programme, it is a complete waste of time, because you miss a programme when it has background information". Screen design was also seen as a problem, with text sometimes occluding the picture or banishing it into a small window. One problem the participants identified for learning with television of any form was that it was normally shared with others, who might well not be interested in language learning: "my two boys would rather watch the Simpsons or something all the time. There is a big fight for the TV".

\section{Implications}

The focus group results played a key role in directing the overall development strategy and influenced some major decisions. One such decision concerned the appropriateness of formal learning structures for iTV based services. Many scenarios for iTV learning have concentrated on formal learning, i.e. where the viewer is explicitly focused on learning as an end in itself, possibly even in the context of a curriculum or class $[4,6]$. Our focus group results indicate that language learners do not perceive (i)TV as a medium for formal learning, but as a form of entertainment that may have the side effect of incidental learning. Even our most fanatical language learners were not keen to watch TV programmes 
specifically made for the language student. In addition, they were aware of the tensions that imposing specifically educational material might have on their fellow-viewers. However, the up-to-date authentic material broadcast on TV was very attractive to them and they perceived it as bringing many valuable learning opportunities. Hence, rather than creating interactive TV programmes specifically for language learning, our strategy should be to add interactive enhancements to existing, engaging, programmes, supporting informal rather than formal learning, via programmes the viewer might watch spontaneously even without language learning opportunities.

Second was a decision on the provision of support for viewers. Our participants appreciated any support that helped them obtain more from their foreign language viewing. In particular multimedia presentation of material, with media complementing each other and providing context, were seen to facilitate understanding: subtitles made it easier to follow rapid speech, gestures and other graphical information expressed extra-linguistic meaning, a visual setting anchored the meaning of spoken language and so on. ITV could scaffold understanding even further, by providing a selection of levels of support in appropriate complementary media, either through the television screen or via a separate device such as the mobile phone. The general enthusiasm for learning on the move suggested the incorporation of the mobile phone. This proposed use of phones has the advantage of not imposing educational material on other viewers, and of giving the learner the opportunity for asynchronous engagement with the programme, after, while or even before it is broadcast. The separation of functions that occurs when using the phone to display support material also answers the fears of those participants who were worried about the speed of synchronised subtitles and the problem of missing the programme itself when attempting to access interactive material. Using the mobile phone alone would make it difficult to deliver engaging and authentic material, mainly because of the technological limitations currently associated with the technology, pointing again to a dual device solution. However, there was a clear generation gap, and the mobile phone was not embraced by older participants.

The results suggest a broad direction for our work on the use of new technologies for language learning using a dual medium approach, taking advantage of the best aspects of each medium, rather than concentrating on a single technology. The next stage was to embody the design concept in a scenario, where the focus group had an important spin-off effect. Scenarios, though widely used, have been criticised as a design tool on the grounds that they are one-dimensional and underdeveloped [9]. The focus group experience allows us to create rounded personas, by grounding them in the characteristics of some of the individuals we talked to. This should give more realism to the scenario and add to its capacity for generating design concepts (ibid.).

\section{Scenario}

Martha, 48, lectures in the English department of the University of the South Coast. She has always been interested in languages, mainly because of her life experiences. After a degree in English and French in Bristol, UK, she spent three years living in Quebec, where her hydro-engineer husband's job had sent him. She kept up her French there via reading and conversation but also by watching popular soap operas, which also gave her some conversational material when chatting to neighbours.

She and the family spend many holidays in France a good reason for keeping her French up to scratch. She has a subscription to a monthly CD magazine in French which she listens to in the car. She likes the songs and poetry that are included and tries to learn them by heart, talking and singing along to herself in the privacy of the car. She also has her car radio tuned to a local French radio station.

Her Quebec experience has taught her just how effective television can be for getting used to other languages and learning about foreign cultures, and this was at the back of her mind when she took out a subscription to satellite TV. She knew that French TV channels were available and harbours a hope of interesting her son Tom (13) and daughter Emma (15) in French. Tom shows no interest in languages: for him French means boring weeks in the French countryside. Emma, however, is keen on French and is hoping to shine in her GCSE exam next term.

Martha has discovered a French TV station that broadcasts with subtitles (in French), which she finds give just the right level of help to allow her to understand the news and dramas without too much concentration. It's useful, as it enables her to see word spelling and also increases word and phrase recognition. However, she finds it difficult to keep up with the speed of subtitles, especially as she's typically doing something else as she watches, whether preparing a meal or talking to the children. The subtitles are usually displayed very fast and it would be helpful if she could adjust them according to her own pace. She can also manage some types of programme without subtitles, but finds it hard to ignore them if 
they're on the screen. She often reads the subtitles rather than trying to make out the speech.

Watching television with her children represents precious "quality time" for Martha, and she certainly doesn't want to make it a chore by insisting they watch educational programmes together. However, she'd like to watch with them while learning some extra odd French words or phrases. She has just read that a new service has become available via cable and satellite, enabling viewers to watch subtitles in the language of their choice and to learn new vocabulary via a personal vocabulary service displayable on the television screen or mobile phone. Viewers can also use their mobile phone to interact with the TV set and learn individually while watching in company. Martha is not a fan of mobile phones, though. She has one just for emergencies, unlike the children who are constant SMS users.

Martha has managed to persuade Tom and Emma that an episode of the police drama Maigret on French TV will be fun to watch. There are English subtitles available on the screen for Tom and Emma. Tom enjoys Maigret, and even recognises a few French words, but the prospect of the news in French is too much for him and he disappears to his room. Martha is happy to watch the news and understands almost everything. Emma is keen to try, with her exams looming, but less confident, so she tries the new service by clicking the red button. The service is on its default setting, which displays numbers and proper names. As the news item is broadcast, the newscaster tells viewers about the tense new situation between Havana and Washington. On the semi-transparent overlay on the screen, the name "La Havane" and its translation, "Havana," are displayed, allowing Emma to grasp this unknown term (see Fig 1.). Emma's quite impressed, especially since the vocabulary she's just seen will also be sent to her mobile, where it will be accessible in her individual learning area (see Fig. 2). She can also change the settings to deliver filtered vocabulary on one of several other themes, e.g. social language, travel and so on. Emma could also use her mobile phone to review the programme sound track on the way to school.

After the news, Martha spots that a classic Truffaut film is on the following evening. Some time during the day she'll make some time to read through the synopsis on the interactive pages so that she won't need to use the subtitles at all [12, pp. 14-15]. If Emma wants to join in, she can access the synopsis beforehand on her phone, and receive subtitles on the phone as she watches. She normally has her mobile with her on the sofa anyway, to text her friends. The unobtrusiveness of the mobile phone approach enables both to enjoy watching the TV as well as giving the sense that they have achieved something worthwhile.

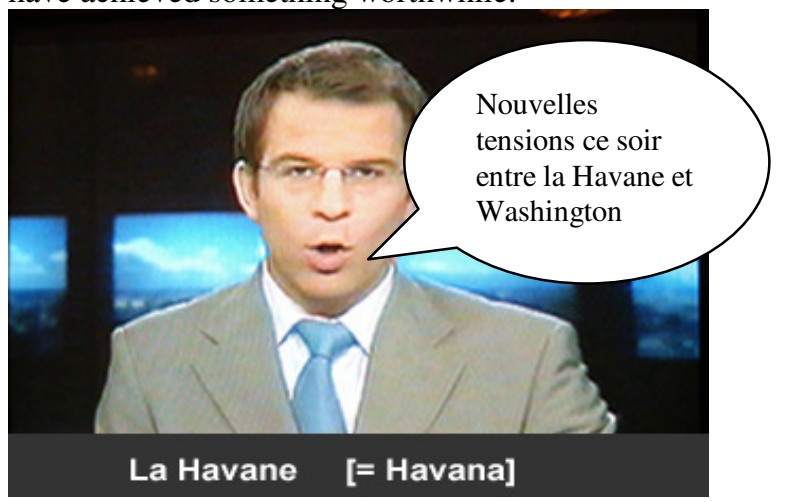

Figure 1. iTV display screenshot

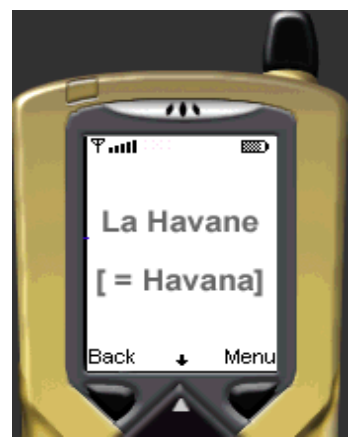

Figure 2. Mobile phone display screenshot

\section{Further Work}

The dual device scenario presented here responds to many of the requirements from the focus group. Television, unlike its rival technology DVD, provides a constantly refreshed, up to date stream of authentic and engaging materials that are of intrinsic interest. Learning in context is made possible, with rich multimedia content providing a comprehensible setting for the new language. Learning on the move is supported, while leisure use of television is respected. Learners can also choose to take advantage of one device without the other, and scaffolded learning opportunities can be provided to suit learner motivation and knowledge level.

The scenario raises a number of questions to be addressed in further work. A first question is the extent to which the services we have sketched answer the needs articulated by language professionals. While they correspond to pedagogically sound principles insofar as they support learning in context using authentic materials [12] they are not a complete solution and will need to be supplemented by other material. In particular, as Sherrington pointed out many years ago, 
TV does not present obvious opportunities for employing speaking and writing skills [13], although the potential is there with mobile phones. In addition, formally structured materials will be needed, particularly for beginners. Details of pedagogy will need to be developed in collaboration with language teaching experts.

A second set of issues concerns the technical feasibility of the dual device approach. We are currently investigating two possible end-to-end solutions based on a multi-tier client/server architecture consisting of the broadcast-end tier, the back-end tier and front-end tier for developing the language learning service.

One solution is to develop a learning management system that can be located in the broadcast-end or back-end tier. This learning management system provides content to both set top box and mobile devices and also holds learning content or learning objects in a semi-structured XML schema. In the frontend tier we have the set top box and WAP enabled mobile devices. Two way communications can be established between set top box and back-end tier through telephone modem, ADSL or broadband cable, while mobile phone devices communicate with the back-end tier through the WAP protocol.

An alternative solution is to use Digital Video Broadcasting (DVB), Java enterprise development solution and Bluetooth technology [15]. The language learning content and mainstream television programme can be encoded and multiplexed before being broadcast via the DVB stream. Multiple audio and video channels can be encoded into the MPEG transport stream. The learning content will be retrieved by a client based Java application located in an $\mathrm{MHP}^{1}$ based set top box. This Java application provides the API required for content retrieval and presentation to the $\mathrm{TV}$ and mobile devices. Java 2 Micro Edition (J2ME) allows the set top boxes and mobile devices to communicate wirelessly through Bluetooth technology.

Although it is a topic rarely explored in learning technology literature, the development of a sound business model for the services also needs to be addressed. Convergent media have the potential to generate additional revenue streams for platform providers and/or broadcasters, which can ultimately benefit learners, but it will be challenging to keep the interests of both sides in balance.

A final set of issues concerns the design of the onscreen and mobile interactions. Despite Robertson et

\footnotetext{
${ }^{1}$ Multi-media Home Platform (MHP) is a European standard for the provision of a common deployment platform for delivering interactive content using Java.
}

al's pioneering CHI paper discussing coordinated iTV and PDA interaction [14], little is known about interacting devices and this will be a further focus for the project. Usability evaluation of iTV poses its own difficulties [16]. We are also exploring the use of personalization techniques for iTV learning[17].

\section{References}

[1] Carroll, J.M. 2000. Five Reasons for scenario-based design. Interacting with Computers, 13, pp. 43 - 60.

[2] Twidale, M. \& Cheverst, K. 2000. Exploring the design space of networked technologies. Proc. of International Workshop on Technologies that Cross Boundaries: Exploring the Gap between Wireless Networks, Bits, Interfaces, and Work Practices, CSCW'00.

[3] Roibas, A.C. \& Sanchez, I.A. 2002. Pathways to MLearning. In Anastopoulou et al (Eds) Proceedings of the European Workshop on Mobile and Contextual Learning, Birmingham, pp. $53-56$.

[4] Bates, P. J., 2003. T-Learning Study: A study into TVbased interactive learning to the home. Available online: http://www.pjb.co.uk/t-learning/contents.htm

[5] Sharples, M. 2000. The design of personal mobile technologies for lifelong learning. Computers and Education, $34,177-193$.

[6] Luckin, R. \& du Boulay, B., 2001. Imbedding AIED in ieTV through broadband user modeling. AIED Proceedings.

[7] Pemberton, L. 2002. The Potential of Interactive Television for Delivering Individualised Language Learning, Proceedings of the Future TV: Adaptive Instruction In Your Living Room (Workshop for ITS 2002),

[8] Underwood, J., 2002, Language Learning and Interactive TV. Proceedings of the Future TV: Adaptive Instruction In Your Living Room (Workshop for ITS 2002)

[9] Nielsen, L. 2002. From user to character-an investigation into user-descriptions in scenarios. Proceedings of DIS 2002.

[10] Fallahkhair, S., J. Masthoff \& L. Pemberton. In press. Learning Languages from Interactive Television: Language Learners Reflect on Techniques and Technologies. Proceedings of EdMedia 2004.

[11] BBC World Wide Press Release, 2003, BBC to provide English language teaching in China via mobile telephones,http://www.bbc.co.uk/pressoffice/commercial/wor ldwidestories/pressreleases/2003/03 march/elt sms.shtml

[12] Meinhof, Ulrike H. 1998. Language Learning in the Age of Satellite Television. Oxford U.P.

[13] Sherrington, R. 1973. Television and Language Skills. Oxford: Oxford U.P.

[14] Robertson, S., Wharton, C., Ashworth, C. and Franske, M., Dual Device User Interface Design: PDA and interactive Television, Proceedings of CHI 1996 Vancouver.

[15] Fallahkhair, S. In press. Media Convergence: An architecture for iTV and mobile phone based interactive language learning. Proceedings of EuroITV 2004.

[16] Pemberton, L. \& Griffiths, R. 2003. Usability evaluation techniques for interactive television. Proc. HCI International. [17] Masthoff, J. \& Pemberton, L., 2003. Adaptive learning via interactive television. Proceedings of PEG 03. 
